\title{
O Adão isolado e a heterogênese do Adão cooperativo: o gestor e o professor nas teses e antíteses entre liberdade e cidadania
}

\author{
Regina Celia Moraes (UniCarioca | IBICT) \\ Rosa L. M. Valim (UniCarioca | EICOS | UFRJ)
}

\section{Resumo}

O século XXI reforça paradigmas para a educação e para o trabalho que estimulam o individualismo e contribuem para a criação de aspectos da personalidade, menos sociais - um Adão isolado. Mas a mente humana é social e intersubjetiva, somos seres coletivos. Qual a participação dos professores, dos gestores nesta realidade? Que respostas daremos no escritório, nas salas de aula, para aqueles que estão sob nossa liderança? Ensinaremos os valores do individualismo ou lhes ensinaremos que há uma heterogênese no exercício da vida que exige coragem, resiliência, persistência e que viver junto com liberdade e cidadania ainda é um jardim sem flores cujo jardineiro se chama "cada um de nós"? Talvez o axioma da liberdade seja aprender a viver junto.

Palavras-chave: Educação, trabalho, pós-modernidade, individualismo, cooperação, incerteza.

\begin{abstract}
The 21st century reinforces paradigms for education and work that stimulate individualism and contribute to the creation of less social aspects of personality - an isolated Adam. But the human mind is social and intersubjective, we are collective beings. What is the participation of teachers and managers in this reality? What answers will we give in the office, in the classrooms, to those under our leadership? Will we teach the values of individualism or teach them that there is a heterogenesis in the exercise of life that requires courage, resilience, persistence, and that living together with freedom a flowerless garden whose gardener calls "each of us"? Perhaps the axiom of freedom is to learn to live together
\end{abstract}

Keywords: Education, work, postmodernity, individualism, cooperation, uncertainty

\section{Introdução}

\begin{abstract}
Somente na convivência com outros, o homem é homem (sic), tanto para Platão como para Aristóteles, a quem pareceu natural a sua existência na comunidade, ou polis, dado que a verdadeira natureza humana só nela pode ser plenamente realizada. O homem não social só poderá ser um animal ou um deus (ARISTÓTELES [1253], apud HORHKEIMER e ADORNO, 1973:49).
\end{abstract}

Precisamos interrogar a nós mesmos sobre o papel da liberdade e da cidadania na educação e no trabalho neste século XXI de tão profundas mutações, no qual entram no jogo coletivo as charmosas e hegemônicas culturas ocidentais e as crenças e valores de culturas desconhecidas, que foram legadas à periferia. Fazem parte também dos desafios para a educação e gestão saber enfrentar diferenças de pensamento, lidar com o desconhecido, ensinar e estimular a fazer sozinho, a ser empreendedor de si mesmo e ao mesmo tempo ensinar e estimular a viver juntos, no sentido do fazer junto, desenvolvendo enquanto trabalha e estuda o sentido da liberdade, do individualismo, da cooperação e da solidariedade técnica.

Sennett (1999, apud BENDASSOLI, 2007) em seu ensaio a corrosão do caráter, relembra Pico della Mirandola (1989 [1486], apud BENDASSOLI) que antecipa os riscos psíquicos da solidão daquele que tem que se construir por si mesmo, sabendo que o mar interior, como os oceanos navegados pelos exploradores, é território não mapeado. (BENDASSOLI, 2007).

Epicuro, filósofo pré-socrático, criou o termo clinámen ${ }^{1}$ (QUARTIM DE MORAES, 1998) para se referir ao 
choque entre os átomos, que, na queda, mudavam suas trajetórias. Trazendo este conceito para o campo social, somos clinamens uns dos outros.

Nos tornamos nós mesmos através dos outros" (1984: 56) (...) a construção social do indivíduo é uma história de relações com outros, através da linguagem, e de transformações do funcionamento psicológico constituídas pelas interações face-a-face e por relações sociais mais amplas. (VYGOTISKY, 1984, apud GOES, 2000: 121$)^{2}$.

Se Vygotisky está correto, o que um indivíduo pode produzir - em conjunto com outras pessoas - é muito maior do que o que produz com base em seus próprios recursos e pensamentos. Parafraseando Vigotsky (1984, passim), há uma zona cooperativa, colaborativa do conhecimento que mostra a responsabilidade de professores e gestores em transformar o desenvolvimento potencial em desenvolvimento real, em usar nos métodos que aplica critérios que evidenciem o individualismo e a cidadania.

Diante da ciência de Vygotisky e das propostas de individualismo da Pós-Modernidade, estamos inseguros diante das 'apelações à ação individual sem assistência (quer dizer, o indivíduo é obrigado a agir praticamente sozinho)'. (BENDASSOLI, 2007).

Estamos diante de um enigma: pode-se combinar liberalismo com comunidade? Pode-se viver juntos e ao mesmo tempo iguais e diferentes? Mas como? Podemos fugir de duas posições igualmente destruidoras, ou seja viver juntos pondo de lado nossas diferenças ou viver separadamente em comunidade homogêneas, que se só se comunicarão pelo mercado e pela violência? (TOURAINE, 1999: 63).

Todo dia, o ser humano prepara-se para a gênese de si mesmo e, quer queira quer não queira, existe em interação com os outros. Este artigo visa colocar frente a frente o Adão isolado, que quer a liberdade, quer individualizar-se e o Adão cooperativo, com as ferramentas sociais da cooperação, da generosidade, da compaixão, do repartir do pão. Somos professores e gestores e podemos juntar os caminhos diante de nós: o sujeito individualizado de Bauman (2008) e o viver junto e cooperativo de Sennett (2012), numa síntese, ainda desconhecida, do processo da mente antropológica.

\section{Metodologia}

Este artigo tem o intento de adensar discussões a respeito dos novos paradigmas para a educação e para o trabalho. Esta investigação possui natureza ontológica e, portanto, demandou pesquisa bibliográfica secundária. Assim sendo, consultaram-se, para o desenvolvimento deste artigo, livros, teses, dissertações e periódicos - todos se encontram registrados nas Referências deste documento. Longe de encerrar discussões sobre o assunto, pretende-se aqui apenas dar um passo a mais no sentido de discutir as complexidades aqui abordadas. Neste sentido, a metodologia empregada pode ser definida pela frase de Isaac Newton: se nós enxergamos mais longe, foi porque subimos nos ombros de gigantes.

\section{Reflexões acerca da pós-modernidade}

\section{O Individualismo do século XXI}

Dispor os membros como indivíduos é a marca registrada da sociedade moderna. Essa atribuição, porém, não foi um ato único como a Criação divina; é uma atividade reencenada todos os dias. A sociedade moderna existe em sua atividade de "individualizar", assim como as atividades dos indivíduos consistem na remodelação e renegociação dia a dia da rede de seus emaranhados mútuos chamada "sociedade". Nenhum dos dois sócios fica parado por muito tempo. E assim o significado da "individualização" continua mudando e sempre assume novas formas - do mesmo modo que os resultados acumulados de sua história passada estabelecem sempre novas regras e fabricam novas apostas para o jogo. A "individualização" agora significa algo muito diferente do que significou 100 anos atrás e do que transmitia nos primeiros tempos da era moderna - os tempos da louvada "emancipação" dos humanos da rede fortemente costurada de independência, vigilância e imposição comunais. (BAUMAN, 2009: 62-63)

Na pós-modernidade estamos separados, mas conectados pela rede, em comunidades, debatendo política, educação, comprando e vendendo, numa vida associativa na qual não precisamos estar face a face com o outro. Vivemos 
hoje em comunidades virtuais como em comunidades territoriais. Cada um desses modelos de comunidade possui seus desafios.

Segundo Levy \& Lemos (2010: 117), podemos apontar alguns desafios ligados às comunidades territoriais, dentre eles destacam-se questões ligadas à democracia local, à vida associativa e comunitária, à ajuda mútua, à educação, ao desenvolvimento econômico, à preservação do meio ambiente, à cultura, ao lazer, aos esportes, à vitalização do laço social em geral. Estamos juntos e sós ao mesmo tempo; conectados e separados.

Fazendo uma parábola no tempo, e aportando em 1997, Guy Debord ${ }^{3}$, em A sociedade do espetáculo, apresenta a sociedade como sistemas centrados na tecnologia, em que o isolamento fundamenta a técnica.

O que liga os espectadores é apenas uma ligação irreversível com o próprio centro que os mantém isolados. O espetáculo reúne o separado, mas o reúne como separado. (DEBORD, 1997).

A estrutura social de uma sociedade e a forma como o aprendizado é estruturado - a maneira como passa da mãe para filha, de pai para filho, do irmão da mãe para o filho da irmã, do xamã para o noviço, dos especialistas mitológicos para o aspirante a especialista - determinam muito mais do que o conteúdo real do aprendizado, não só a forma como os indivíduos aprenderão a pensar, mas como o acúmulo de aprendizado, a soma total das peças separadas de habilidades e conhecimento é compartilhado e utilizado. (MEAD apud BAUMAN, 2009: 158)

Não há volta do momento em que estamos vivendo e na arena do progresso "individualmente, nós resistimos; individualmente eu caio" (BAUMAN) ${ }^{4}$.

O século XXI nasce sob o signo da informação, que, por ser abundante, confunde, mas também cria a condição basilar para a formação do sujeito político e a recriação progressiva e permanente da democracia política. Esta relação dialética é consequência do ajuste dos mapas cognitivos, da subjetividade e da intersubjetividade e estabelece a pedra de toque para o contínuo desenvolvimento da democracia. Dentro deste contexto, tem-se que os produtos midiáticos on-line representam os novos paradigmas da pós-modernidade e é especialmente através deles que se dá o imbricamento da comunidade virtual com a comunidade territorial.

A quase ubiquidade destas mídias dinamiza todo o processo democrático com os distintos grupos representativos da sociedade, que escolhem consumir dados e informações, inclusive on-line, visando ao conhecimento.

O consumo destes dados e informações passa por fatores subjetivos relacionados a questões individuais, mas também culturais - crenças e descrenças estabelecidas - de acordo com Morin (MORIN, 1986).

Dentro deste contexto, tem-se que agentes econômicos e sociais vêm disputando espaços virtuais para debater, e isto pode levar progressivamente à criação do espaço público, ao aperfeiçoamento da democracia local, já que a comunicação dá-se sem constrangimentos.

Com o aporte das tecnologias digitais, as cidades podem aperfeiçoar a democracia local. As ágoras virtuais podem renovar as formas da deliberação e do debate político. (LÉVY \& LEMOS, 2010:165)

A informação torna-se uma entidade consiliente ${ }^{5}$, pois liga fatos e teorias para criar novas bases explanatórias, e isso viabiliza um "salto conjunto" de conhecimento através das disciplinas.

Há um ser coletivo, político, transitando nas redes sociais, interagindo, e as novas tecnologias de informação e comunicação (TICs) viabilizam a recepção de dados e informações, a expressão de opiniões, a interação de agentes econômicos e sociais diversos. E não se trata de uma oposição simplória às antigas tecnologias, mas de uma mudança nas práticas sociais e comunicacionais. As tecnologias estimulam a criação de um indivíduo livre, mas político, ligado à cidadania e às redes sociais, que podem ser grandes aliadas na formação do homem (sic) público de Sennett (2001, passim). 


\section{Tudo o que é sólido se desmancha no ar}

A modernidade se construiu sobre a renúncia do instinto e impõe grandes sacrifícios à sexualidade e à agressividade do homem. $\mathrm{O}$ anseio de liberdade dos indivíduos pós-modernos é dirigido às formas e exigências particulares da civilização, contra esta civilização que impõe submissão. A pós-modernidade difere da modernidade, pois enquanto na modernidade o indivíduo procura segurança em detrimento da liberdade, na pós-modernidade o indivíduo decide sacrificar a segurança para obter a liberdade (BAUMAN, 1998: 8).

Foi entre 1970 e 1980 que o desmantelamento da tradicional ordem começou a ser observado (TOURAINE, 2006). Por meio de um processo dialético, surgiram novos paradigmas, pensamentos, atitudes e comportamentos. Conforme sublinha Touraine, os paradigmas ${ }^{6}$ mudaram por conta do surgimento de novas variáveis insurgentes (TOURAINE, 2006), como desemprego, pauperismo, migrações, novas tecnologias, envelhecimento da população. A modernidade cede lugar, então, à pós-modernidade ${ }^{7}$, em que - um exemplo de novo paradigma - "ser" significa um novo começo permanente (BAUMAN, 1998: 20). A estrutura, relacionada à complexa teia social, rompe-se então (TOURAINE, 2006). Nota-se um ajustamento que o velho modelo começa a sofrer para adequar-se aos novos tempos, à pós-modernidade e às suas variáveis.

Contrapondo Touraine (2006), o desmantelamento da tradicional ordem não começou em 1970-1980. Morgan (Apud ENGELS 1953 [1884, 1891]; PAIVA, 2003: 37 a 44) faz uma análise do surgimento deste sujeito individualizado, que vivia em comunidade e se descobre livre, único, conquistador de territórios. Parafraseando Engels (1953: 46, 47, 48, 49 \& passim), a jornada da formação deste ser humano cultural, isolado, menos social, surge na migração do eixo do Matriarcado para o Patriarcado, quando os seres humanos, vivendo nas antigas gens, migraram para um novo patamar, devido a um novo modelo de filiação e casamento, tudo fundado no regime primitivo de acumulação de bens e na antropológica jornada da formação do Estado, a partir do conceito de família monogâmica, que perde progressivamente os traços e laços comunitários.

Na narrativa do historiador Morgan, esta comunidade primitiva configurava o Matriarcado. A mudança do eixo para o Patriarcado surge junto com o reconhecimento da filiação: quem são os meus filhos, para que possa lhes deixar a minha herança? Instaura-se na mente humana o regime de acumulação de bens, protoforma do Capitalismo. Patriarcado e acumulação de bens surgiram juntos na formação do sujeito individual, que se desliga dos laços sociais da comunidade, na trajetória do Adão isolado. 'A propriedade privada se sobrepõe - a partir do regime de acumulação de bens - à propriedade coletiva, (...) a riqueza não pertencia mais ao grupo, mas era concentrada na família (PAIVA, 2003:38), que deu origem ao Estado.

Como está sendo apresentado neste artigo, a jornada do Adão isolado, ecológico, mitológico se insere em uma narrativa que continua presente e se adensa neste século XXI disputando espaço na mente social, na saga de viver junto, na cidadania da pólis, que precisa ser recriada no progressivo drama de se individualizar e ao mesmo tempo aprender a viver junto.

É bom lembrar que estamos dentro de uma antiga estratégia que mantém os 95\% mais pobres da população mundial ocupados em hostilidades étnicas e religiosas. Se eles puderem se distrair do seu próprio desespero com pseudoeventos criados pela mídia, incluindo aí ocasionais guerras sangrentas, os super -ricos pouco terão a temer (BAUMAN, 2013:43).

Não será simples a tarefa de professores e gestores: trazer ao mundo em meio ao Capitalismo atual um ser livre e cooperativo que nasce na incubadora antropológica das teses e antíteses do trabalho e capital; do individualismo e viver junto; do liberalismo e cooperação. 


\section{A cooperação}

Richard Sennett (2012) fala da cooperação como uma habilidade - ou seja, é desenvolvida em conjunto, de forma participativa e se incorpora nos indivíduos como um conhecimento tácito, passando a fazer parte do comportamento em sociedade. A forma de viver cooperativa se transmite pela convivência. Parafraseando Bakhtin $^{8}$ (2008), a intersubjetividade é anterior à subjetividade, ou seja, para sermos nós mesmos, temos que primeiro dialogar, cooperar, observar, copiar, imitar, para só depois sermos nós mesmos e nos individualizarmos.

Tocqueville tem um texto que retrata com muita delicadeza esta perda dos laços comunitários:

Cada pessoa, mergulhada em si mesma, comporta-se como se fora estranha ao destino de todas as demais. Seus filhos e seus amigos constituem para ela a totalidade da espécie humana. Em suas transações com seus concidadãos, pode-se misturar a eles sem, no entanto, vê-los; toca-os, mas não os sente; existe apenas em si mesma e para si mesma. E se, nestas condições, um certo sentido de família ainda permanecer em sua mente, já não lhe resta sentido de sociedade. (TOCQUEVILLE, Apud SENNETT, 2001)

Bauman (2008) afirma que a nova ordem mundial se parece com uma nova desordem mundial.

Derrubar os portões e abandonar qualquer pensamento de política econômica autônoma é a condição preliminar de elegibilidade para receber a assistência financeira dos bancos mundiais e fundos monetários. É de Estados fracos que esta ordem mundial ${ }^{9}$ precisa para se manter e se reproduzir. Os Estados fracos podem ser reduzidos com facilidade ao útil papel de delegacias locais, assegurando a módica ordem necessária para a condução dos negócios, mas sem que sejam temidas como um freio efetivo à liberdade das companhias globais (BAUMAN, 2008).

Esta narrativa traz agora um fenômeno paradoxal e enlouquecido, uma exigência transtornada de redistribuição do poder e as lutas sociais que se instauram mostram traços culturais individualizados.

Toda sociedade até hoje existente assentou-se (...) no antagonismo de classes opressoras e oprimidas. [...] Homem livre e escravo, patrício e plebeu, barão e servo, mestre de corporação e companheiro, numa palavra, opressores e oprimidos, em constante oposição, têm vivido numa guerra ininterrupta, ora aberta, ora disfarçada (...).(MARX \& ENGELS, 1847, 1848, 1951)10

E este antagonismo não cessa, apenas ganha novos contornos:

Vivemos (hoje) um momento de passagem (...) do modelo vertical ao horizontal, do up/down ao in/ out, da classe ao centro/periferia. [...]. (...) Não é o modelo vertical de classes o que melhor pode descrever esta nova configuração social. Agora, encontramo-nos diante de um esquema horizontal, dentro/ fora, incluído/excluído. (TOURAINE apud OLIVEIRA, 2000: 17-18)

A sociedade cultural é individual, um fenômeno antropológico, antigo, global, que surge localizado, a partir do deslocamento do eixo para um novo paradigma cultural, no qual crenças que foram marginalizadas se insurgem vestidas para uma guerra na qual a teleologia ${ }^{11}$ só se descobre ao olhar para trás, sendo totalmente desconhecida enquanto está sendo urdida, mas que prefigura a jornada do ser humano em direção a si mesmo, cooperativo e livre.

Quando Deus perguntou a Caim onde estava Abel, Caim replicou, zangado, com outra pergunta: "Sou por acaso o guardião de meu irmão?". O maior filósofo ético do nosso século, Emmanuel Levinas, comentou que dessa pergunta zangada de Caim começou toda a imoralidade. É claro que sou o guardião do meu irmão; e sou e permaneço uma pessoa moral enquanto não pergunto para uma razão especial para sê-lo.

Quer eu aceite, quer não aceite, sou o guardião do meu irmão, pois o bem-estar do meu irmão depende do que eu faço ou me abstenho de fazer. Sou uma pessoa moral porque reconheço esta dependência e aceito esta responsabilidade. No momento em que questiono esta dependência e esta responsabilidade e razões para que me preocupe (como fez Caim), renuncio à minha responsabilidade e deixo de ser um ser moral. A dependência de meu irmão, ou a responsabilização pelo outro, é o que me faz um ser ético. A dependência e a ética estão juntas, e juntas elas caem (BAUMAN, 2008). 


\title{
Organizações que aprendem
}

Bertalanffy (2015), em sua Teoria Geral dos Sistemas, enfatiza que tudo está unido a tudo, e que cada organismo não é um sistema estático fechado ao mundo exterior, mas, sim, um processo de intercâmbio com o meio circunvizinho.

Cada escola, cada universidade, cada empresa, cada professor, cada gestor tem papel fundamental na formação das pessoas e precisa buscar concebê-lo de forma conectada com a autonomia, a consciência crítica, a liberdade, o respeito aos ideais de viver junto.

Adotar o Princípio da Incerteza ${ }^{12}$ de Heisenberg ${ }^{13}$ ao se pensar a educação e o trabalho ajuda a representar o Modelo Organizacional como algo inacabado sempre, não por ineficiência, mas por lógica.

Ao trazer a incerteza para o contexto das organizações, deve-se pensar se estamos preparados e atentos para captar as mudanças - pequenas ou grandes - que se insurgem dentro e fora das organizações. As organizações são seres em permanente transformação - na maioria das vezes imperceptíveis aos olhos desatentos. Tendo a incerteza como uma ferramenta do pensamento, é possível captar o cenário integrado onde se apresentam tecnologias, novas práticas, novos métodos, mercado, os limites pessoais. O mundo novo nasce todos os dias, e é preciso notar sua presença ou ausência e, com pensamento crítico, ousar adotar o novo, educar e liderar para o bem comum. No final, todos somos salvaguardas dos valores permanentes da humanidade, na difícil - mas imprescindível - percepção do nosso destino comum e da importância de ensinar o indivíduo a ser ele mesmo, livre, mas com a habilidade de viver junto.

Protágoras, um filósofo grego que viveu por volta de 500 a.C., dizia que "o ser humano é a medida de todas as coisas". No entanto, o paradigma atual intensificou-se e reduziu o humano a um meio, a um recurso, e, através das gerações, muitos indivíduos acabam adaptando-se. E, assim, são reproduzidos novos reprodutores, num gradiente monótono que aponta para uma única direção: números, estatísticas, valores, mas só os financeiros. Pode-se mudar? É possível interceptar o futuro enquanto está sendo gestado e, progressivamente, criar uma nova forma de trabalhar e ensinar, racional e cooperativa?

Phillip Kotler nos dá esperanças, pois afirma que hoje se nota no mercado o seguinte movimento: organizações centrando suas estratégias em valores, não monetários, mas sim éticos e morais (KOTLER et al., 2012).

\begin{abstract}
Ao longo dos últimos 60 anos, o marketing deixou de ser centrado no produto (marketing 1.0) e passou a ser centrado no consumidor (marketing 2.0). Hoje vemos o marketing transformando-se mais uma vez, em resposta a nova dinâmica do meio. Vemos as empresas expandindo seu foco dos produtos para os consumidores e para as questões humanas. (KOTLER et al., 2012).
\end{abstract}

Pico dela Mirandola (1989 apud BENDASSOLI, 2007) exalta a criatura humana por sua capacidade e liberdade para determinar a realidade que a cerca, incluindo, na mais elevada instância, sua própria existência, aquilo que deseja ser.

Tudo é novo e antigo, tudo é muito sensível, e, neste sentido, Marx tem razão, pois 'tudo que é sólido se desmancha no ar.' 'Te megala panta episphale' (PLATÃO, apud CARNEIRO LEÃO, 2013) - tudo que é grande precipita-se numa avalanche de transformações.

Kotler afirma, ainda, que este movimento não é necessariamente simples ou natural, mas fruto de escolhas estratégicas, e surge em resposta a demandas de mercado (KOTLER et al., 2012). Ora, mudanças só se estabelecem em empresas formadas por profissionais comprometidos, forjados nas academias e lapidados pelo mercado. Ou, nas palavras de Senge, as organizações só aprendem através de indivíduos que aprendem (Senge, 1990: 135). 


\section{Conclusões}

Heráclito da cidade de Éfeso ${ }^{14}$ foi o primeiro filósofo a formular o pensamento dialético, que afirma que a mudança é uma constante em todos os processos da vida (tanto de pessoas quanto de organizações). Este eterno devir (vir-a-ser) convida-nos a observar e aprender com as pessoas - como atuam e aprendem. Só assim poderemos aprender e apreender o mundo à nossa volta, só assim somos capazes de grandes transformações, só assim poderemos adquirir valores mais nobres da nossa humanidade comum. Esta antecipação permite conceber, num espectro mais amplo, o mundo do qual fazemos parte e que está em constante e progressiva evolução, permite conceber o que precisamos mudar em nós mesmos.

O que temos por ora é a falácia de uma sociedade apregoada pelas revoluções industriais como uma sociedade que traria o progresso para todos e que se mostra, hoje, separada do social, pois as revoluções industrial, tecnológica e informacional não trouxeram progresso para todos os povos. Ao contrário, confinou o bem comum nas mãos de alguns poucos grupos. Hoje há um apelo ao individualismo, ao viva e faça sozinho, em detrimento da cidadania.

Saramago tem razão, não há um resultado final, e o destino não está esperando desde o princípio, sem se mover, para referendar a perda da nossa humanidade conjunta. Ora, pelo contrário, o destino hesita muitíssimo, tem dúvidas, leva tempo a decidir-se (SARAMAGO, 1994) ${ }^{15}$.

Estamos diante da esfinge da pós-modernidade, que seduz para ensinar o individualismo como uma ferramenta isolada do conjunto social. Ela apregoa pelas estradas que cada um siga o seu caminho de forma independente, que cada um cuide de si. Mas Bauman alerta que 'a dependência e a ética nascem juntas e juntas caem' (2008). Tese e antítese se confrontam nas empresas e nas escolas, na universidades, e as sínteses estão sendo construídas. 'A contingência, não o determinismo, é a base do nosso complexo presente' (BAUMAN, 2013, 64).

Somos os responsáveis, professores, filósofos e gestores, pelo ensinamento de valores, os transmitidos no silêncio, no olhar, no comportamento, na fala, nas regras. Sendo assim, temos responsabilidade com nossa forma de agir: incentivar o ser humano a ser ele mesmo, individualizado, rico em valores individuais - o Adão isolado -, cujo 'mar interior é um território não mapeado' (PICO DELLA MIRANDOLA, 1989 [1486], apud BENDASSOLI) e estimulá-lo para que atue em conjunto com o grupo, a fim de que desenvolva cooperação e aprenda progressivamente as bases do viver junto de Sennett, na heterogênese progressiva do Adão cooperativo, que se forja livre e cooperativo na incubadora da liberdade individual.

O que virá primeiro: a liberdade ou o viver junto? Bakhtin diz que a intersubjetividade é anterior à subjetividade (2008). No contexto das teses e antíteses de liberdade e cidadania, cabe ao professor e ao gestor - enquanto aprendem - criarem os métodos e diretrizes capazes de integrar liberdade e individualismo à habilidade de cooperar e viver junto!

\section{Notas}

1. Clinâmen é um conceito central na doutrina atomista de Epicuro (filósofo pré-socrático) e simboliza o desvio imprevisível de átomos, cuja representação é a queda aleatória dos átomos, que no choque entre si, mudam suas trajetórias. O nome foi aplicado por Lucrécio, poeta e filósofo latino que viveu no século I a.C - ao estudar a doutrina atomista de Epicuro. De acordo com Lucrécio, o desvio imprevisível ocorre "em nenhum lugar ou tempo fixo": Significa que "quando átomos se movem (..) no espaço em um tempo completamente incerto e em lugares incertos", (...) a natureza se reproduz. Este desvio imprevisível e o choque mudam trajetórias e simbolizam uma mudança de mentalidade - uma nova visão - é isto que se chama clinámen

2. http://www.faculdadefar.edu.br/artigo-cronica/detalhe/id/21

3. A Sociedade do Espetáculo - Rio de Janeiro: Editora Contraponto, 1997

4. A Sociedade Individualizada

5. Termo criado por William Whewell em 1840 (The Philosophy of the Inductive Sciences) para indicar um salto conjunto" do conhecimento entre e através das disciplinas, por meio da ligação de fatos e de teorias, para criar novas bases explanatórias (BRAGA in CIÊNCIA DA INFORMAÇÃO, 1998, 9).

6. Entenda-se o termo paradigmas, a partir do viés de Alain Touraine (2006), como as variáveis sociais e culturais que, dentro do tempo ao qual pertencem, procuram espelhar a vanguarda do momento. 
7. Segundo BAUMAN, na pós-modernidade o homem valoriza a liberdade em detrimento da segurança. A pós-modernidade vive num estado de permanente pressão para se despojar de toda a interferência coletiva no destino individual, para desregulamentar e privatizar (BAUMAN; 1998; 26).

8. (1895-1975) - foi um filósofo e pensador russo, pesquisador da linguagem humana

9. (que está sendo repelida) - grifo dos autores deste livro

10. https://chasqueweb.ufrgs.br/ slomp/filosofia/marx-manifesto.htm

11. Segundo Platão e Aristóteles, é o estudo filosófico dos fins, do propósito, objetivo ou finalidade.

12. Um emprego fixo traz segurança à pessoa, enquanto um trabalho autônomo dá liberdade. Zygmunt Bauman diz que a Modernidade sacrificou a segurança

13. agora tudo é relativo e passamos conviver com a incerteza.

14. Werner Karl Heisenberg (1901 - 1976) - físico alemão que recebeu o Prêmio Nobel de Física em 1932"pela criação da mecânica quântica

15. aprox. 535 a.C. -475 a.C

16. José Saramago, in 'Cadernos de Lanzarote, 1994

\section{Contato das autoras}

Regina Celia Moraes | rmoraes@unicarioca.edu.br

Rosa L. M. Valim | rvalim@unicarioca.edu.br

\section{Referências Biliográficas}

BAKHTIN, M. Dialogismo e Construção do Sentido. Organização: Beth Brait. São Paulo: Editora Unicamp, 2008.

BAUMAN, Z. Sociedade Individualizada: Vidas contadas e histórias vividas. Rio de Janeiro: Zahar, 2008.

. Cultura no Mundo Líquido Moderno. Rio de Janeiro: Zahar, 2013.

BENDASSOLI, P. F. Identidade e Trabalho em Tempos Sombrios. São Paulo: Idéias e Letras, 2007.

BENJAMIN, W. O Anjo da História. São Paulo: Editora Autêntica, 2013.

Vol. I - 8a Ed. 2012.

Magia e Técnica, Arte

BERTALANFFY, L V. Teoria Geral dos Sistemas. Petrópolis: Vozes, 2015.

CIÊNCIA DA INFORMAÇÃO, Ciências sociais e interdisciplinaridade / Ana Lucia Staines de Castro...[et al.]; organização de Lena Vania Ribeiro Pinheiro; prefácio de Gilda Maria Braga. - Brasília; Rio de Janeiro: Instituto Brasileiro de Informação em Ciência e Tecnologia, 1999.

DEBORD, G. A Sociedade do Espetáculo. Rio de Janeiro: Editora Contraponto, 1997.

ENGELS, F. A origem da família, da propriedade privada e do Estado. Rio de Janeiro: Editorial Vitoria Limitada, 1953 [1884, 1891]

EPICURO. Obras completas. 7.ed. Trad. José Vara. Madrid: Edciones Cátedra, 2007.

GÓES, M. C. R. A formação do indivíduo nas relações sociais: Contribuições teóricas de Lev Vigotski e Pierre Janet. In: Educação \& Sociedade, ano XXI, no 71, Julho/00. Disponível em: <http://www.scielo.br/pdf/es/v21n71/a05v2171.pdf>

HABERMAS, J. Teoria da ação comunicativa. São Paulo: Martins Fontes, 2000.

HOELLER, S. A Gnose de Jung e os Sete Sermões aos Mortos. Rio de Janeiro: Cultrix. 1998

HORKHEIMER, M., ADORNO, T. Temas Básicos de Sociologia. São Paulo: Editora Cultrix, 1973. 205 p.

KOTLER, P; KARTAJAIA, H; SETIAWAN, I. Marketing 3.0. São Paulo: Elsevier, 2012.

LEÃO, E. C. Filosofia Contemporânea, Petrópolis: Editora Daimon, 2013

LEMOS, A.; LÈVY, P. O futuro da internet: em direção a uma ciberdemocracia. São Paulo: Paulus, 2010.

MARX, K.; ENGELS, F. Manifesto do Partido Comunista. Londres: publicado em dezembro de 1847 - janeiro 1948; em espanhol em 1951, traduzida da edição alemã de 1848. Disponível em: <https://chasqueweb.ufrgs.br/ slomp/filosofia/marx-manifesto.htm>

MIRANDOLA, P. Discurso sobre a dignidade do homem. (M. de L.D. Ganho, Trad.). Lisboa: Edições 70.

OLIVEIRA, A. Educação e exclusão: a contribuição da Filosofia da Educação na determinação conceptual. In: Revista Perspectiva, vol.18, n.34, p.11-31, jul./dez. 2000. 
PAIVA, R. O espírito Comum - Comunidades, Mídia e Globalismo. Rio de Janeiro: Mauad, 2003.

QUARTIM DE MORAES, J. Epicuro: as luzes da ética. São Paulo: Moderna, 1998. (Coleção Logos).

RICHE, G. A.; MONTE ALTO, R. As organizações que aprendem, segundo peter senge: "a quinta disciplina". In: Cadernos discentes COPPEAD, Rio de Janeiro, n. 9, p. 36-55, 2001. Disponível em: <http://www.mettodo.com.br.pdf>

SENGE, P. M. A quinta disciplina. São Paulo: Editora Best Seller, 1990.

SENNETT, Richard, O Declínio do Homem Público. Rio de Janeiro: Companhia das Letras, 2001

A Corrosão do Caráter. Rio de Janeiro: Editora Record, 1999.

Juntos: os Rituais, os Prazeres e a Politica da Cooperaçao. Rio de Janeiro: Editora Record, 2012.

TOURAINE, Alain. Um novo paradigma: para compreender o mundo de hoje. Petrópolis: Vozes, 2006.

. Poderemos Viver Juntos. Petrópolis: Vozes, 1999.

VYGOTSKY, L.S. A formação social da mente. São Paulo: Martins Fontes, 1998.

Pensamento e linguagem. Trad. M. Resende, Lisboa, Antídoto, 1979. . A formação social da mente. Trad. José

Cipolla Neto et alii. São Paulo, Livraria Martins Fontes, 1984. 